Hopman, P., Schellevis, F.G., Rijken, M. Health-related needs of people with multiple chronic diseases: differences and underlying factors. Quality of Life Research: 2015

\begin{tabular}{|l|l|}
\hline $\begin{array}{l}\text { Postprint } \\
\text { Version }\end{array}$ & 1.0 \\
\hline Journal website & http://link.springer.com/article/10.1007\%2Fs11136-015-1102-8 \\
\hline Pubmed link & $\underline{\text { http://www.ncbi.n/m.nih.gov/pubmed/26338192 }}$ \\
\hline DOI & $10.1007 / \mathrm{s} 11136-015-1102-8$ \\
\hline
\end{tabular}

This is a NIVEL certified Post Print, more info at http://www.nivel.eu

\title{
Health-related needs of people with multiple chronic diseases: differences and underlying factors
}

Petra Hopman1 François G. SChellevis1,2 Mieke RiJKen1

\begin{abstract}
Purpose To examine the health-related needs of people with multiple chronic diseases in the Netherlands compared to people with one chronic disease, and to identify

different subgroups of multimorbid patients based on differences in their health problems

Methods Participants were 1092 people with one or more chronic diseases of a nationwide prospective panel study on the consequences of chronic illness in the Netherlands. They completed the EQ-6D, a multi-dimensional questionnaire on health problems (October 2013). Chi-square tests and analyses of variance were performed to test for differences between multimorbid patients and patients with one chronic disease. To identify subgroups of multimorbid patients, cluster analysis was performed and differences in EQ-6D scores between clusters were tested with Chisquare tests.

Results

Multimorbid patients (51\% of the total sample) experience more problems in most health domains than patients with one chronic disease. Almost half (44 \%) of the multimorbid people had many health problems in different domains. These people were more often female, had a smaller household size, had a lower health literacy, and suffered from more chronic diseases. Remarkably, a small subgroup of multimorbid patients ( $4 \%$, mostly elderly males) is characterized by all having cognitive problems.

Conclusions

Based on the problems they experience, we conclude that patients with multimorbidity have relatively many and diverse health-related needs. Extensive healthrelated needs among people with multimorbidity may relate not only to the number of chronic diseases they suffer from, but also to their patient characteristics. This should be taken into account, when identifying target groups for comprehensive support programmes.
\end{abstract}


Hopman, P., Schellevis, F.G., Rijken, M. Health-related needs of people with multiple chronic diseases: differences and underlying factors. Quality of Life Research: 2015

\section{INTRODUCTION}

Due to rapid ageing and greater longevity of the Western population as well as increasing improvement of medical care, a growing number of people are living with a chronic disease [1]. An increasing proportion of these chronically ill people suffers from multimorbidity $[2,3]$, which refers to the co-occurrence of multiple chronic diseases within a person $[4,5]$. Especially among older people the prevalence of multimorbidity is very high: among people over age 65 and 85 the proportion of individuals with multiple chronic diseases is estimated at about 65 and $85 \%$, respectively (e.g. [6, 7]). People with one or more chronic diseases often experience problems in many health domains, which is likely to impair their quality of life [ 8 , 9]. These health problems can be merely physical, but also psychological, cognitive, social, and/or practical. Health problems may be even more common among people with multiple chronic diseases. For instance, Rijken and colleagues [10] found significantly lower levels of physical functioning among patients with cardiovascular disease, chronic respiratory disease, diabetes mellitus, or thyroid dysfunction who also suffered from a comorbid disease than among patients with the same chronic diseases who did not have comorbid diseases. Differences in mental health were, however, not found between these patient groups with or without multimorbidity. Given these findings, it is interesting to examine to what degree and how (i.e. in which health domains) people with multimorbidity are worse off compared to people with a single chronic disease. The occurrence of health problems in several domains can be considered an indication of the various needs for care and support of chronically ill people - for instance medical care combined with home care and informal care in case of experiencing problems with mobility, self-care or usual activities, or medical care combined with psychological counselling when people with (somatic) multimorbidity experience anxiety or depression because of their health condition. In order to adequately address these needs, the delivery of (integrated) care from different care sectors (i.e. medical care, social care, psychological support, home help, and personal assistance) may be necessary, in particular for multimorbid patients with many and various health problems [11]. To allocate resources for care and support as efficiently as possible, it is important to identify those multimorbid patients who are most in need

for comprehensive care and support. Since different chronic diseases, or combinations of chronic diseases, may be associated with specific health problems, multimorbid patients cannot be considered homogeneous with respect to their needs. Moreover, apart from illness-related factors, needs might also relate to individual patient characteristics such as socio-demographic characteristics (e.g. age, gender, education level), health literacy (important for patients to communicate their needs and preferences; [12]), and living situation [9]. Optimally and efficiently targeting care and support for people with multiple chronic diseases therefore requires the identification of the most vulnerable patient groups and their needs. The induction of profiles of groups of multimorbid patients with specific needs within one or more health domain(s) will allow the health and social care

system to improve the quality of care for these people as a whole-for example by implementing comprehensive care programmes [13, 14].

The aim of this study was therefore to distinguish different groups of multimorbid patients based on their varioushealth problems and to identify those with the highest 
Hopman, P., Schellevis, F.G., Rijken, M. Health-related needs of people with multiple chronic

diseases: differences and underlying factors. Quality of Life Research: 2015

or most comprehensive needs for care and support. The current research addresses the following research questions: 1 . How do health problems of people with multimorbidity differ from health problems of people with one chronic disease? 2. Which subgroups of multimorbid people can be distinguished on the basis of their health problems? 3. Which patient and illness characteristics underlie the different patterns of health problems among multimorbid patients?

\section{METHODS}

\section{Participants and procedures}

To answer our research questions, we analysed data from the 'National Panel of people with Chronic illness or Disability' (NPCD), a nationwide prospective panel study on the consequences of chronic illness in the Netherlands [15]. Panel members were recruited from the patient files of general practices (national random samples of general practices were drawn from the Netherlands registration of General Practice, e.g. [16]). Patients were selected based on the following criteria: diagnosis of a somatic chronic disease by a certified medical practitioner, aged C 15 years, being non-institutionalized, being aware of the diagnosis, not being terminally ill [life expectancy [6 months according to the general practitioner (GP)], being mentally able to participate, and having sufficient mastery of the Dutch language. Patients who met the selection criteria were invited by their general practitioner to participate in the panel and were asked to participate for a maximum period of 4 years. Patients who agreed to participate filled in selfreport questionnaires twice a year. In addition, their general practitioner provided medical data on the patient at inclusion. There are valid reasons to consider the panel to be representative for the non-institutionalized chronically ill population of 15 years and older in the Netherlands. I Informed consent was obtained from all individuals participants included in this study. NPCD is registered with the Dutch Data Protection Authority; all data were collected and handled in accordance with the privacy protection guidelines of the Authority. The main measures of this study are from a questionnaire that was sent in October 2013 to a sample of 1424 panel members with at least one chronic disease diagnosed by a medical practitioner. Thousand and ninety-two patients $(77 \%)$ returned the questionnaire. Since this questionnaire did not contain a health literacy measure, we added data on health literacy from a questionnaire that was sent in April 2013 to a sample of 1681 panel members ( $80 \%$ response rate). Seventy-eight per cent of the respondents on the October questionnaire also completed this April questionnaire.

\section{Measures}

\section{Health problems}

Health problems were assessed by the EQ-6D [18, 19], a multi-dimensional instrument based on the EQ-5D [20]. The EQ-6D consists of six items assessing patients' selfreported problems with regard to (1) mobility, (2) self-care, (3) usual activities, (4) pain/discomfort, (5) anxiety/depression (all similar to EQ-5D), and (6) cognitive functioning. The six items are scored on a three-point scale: 'no problems' (1), 'some problems' (2), and 'extreme problems' (3). 
Hopman, P., Schellevis, F.G., Rijken, M. Health-related needs of people with multiple chronic diseases: differences and underlying factors. Quality of Life Research: 2015

\section{Loneliness}

To assess problems in the social domain (not covered by the EQ-6D), we included the Loneliness Scale developed by de Jong-Gierveld and Kamphuis [21] and validated by van Tilburg and de Leeuw [22]. This scale consists of 11 items assessing feelings of belonging and missing social relationships. After recoding the positively formulated items, a scale score is computed by averaging the items scores, resulting in a range from 0 ('no loneliness') to 11 ('severe loneliness').

\section{Overall quality of life}

Besides the domain-specific dimensions mentioned above, we incorporated two items to assess overall affective and cognitive quality of life [23]. General feelings of happiness and life satisfaction were measured with the statements 'To what degree do you consider yourself a happy person?' and How satisfied are you with the life you are currently living?'. In accordance with Statistics Netherlands, the items were scored on five-point Likert scales, ranging from 'extraordinarily satisfied' (1) to 'not so satisfied' (5). Items were reversely scored, so that higher scores indicate more happiness/satisfaction.

\section{Patient characteristics}

Patients were asked about their age, gender, highest level of education ['low' (vocational training), 'middle' (high school), and 'high' (college or university)], and living situation ('living with a partner' versus 'living without a partner'). Moreover, health literacy was measured with the 14-item Health Literacy Questionnaire [24] that indicates how often patients have had trouble with, or have performed certain actions in relation to health information. After recoding negatively stated items and computing average scores, the total range is from 1 (low health literacy) to 4 (high health literacy). In our sample, the Cronbach's alpha was .92.

\section{Illness characteristics}

Medical diagnoses of somatic chronic diseases were derived from the patient records of participants' GPs (with permission of the participants). GPs registered patients' diagnosed chronic diseases using the International Classification of Primary Care [25]. GPs were instructed to register all somatic diseases 2 that had been agreed upon by the National Council of Public Health [26] as being 'chronic by definition', i.e. not fully curable, or 'with a chronic course in this particular patient', i.e. with a duration of at least 12 months since the patient's first contact with the GP because of the disease. Based on the number of recorded medical diagnoses, we computed a dichotomous variable 'multimorbidity', distinguishing patients diagnosed with only one chronic disease from those with more than one chronic disease. The GPs also recorded the dates of diagnosis, from which we computed the illness duration (in years), based on the first diagnosed chronic disease (in case of multimorbidity). GPs also rated patients' health status on four dimensions, i.e. 'life threateningness', 
Hopman, P., Schellevis, F.G., Rijken, M. Health-related needs of people with multiple chronic diseases: differences and underlying factors. Quality of Life Research: 2015

'progressive deterioration', 'episodic course', and 'medical controllability'; possible categories were 'to a lesser extent' (1), 'neutral' (2), and 'to a greater extent' (3).

\section{Data analyses}

In order to describe the study sample and differences between multimorbid people and people with a single chronic disease (research question 1), we performed a series of Chi-square tests and analyses of variance (ANOVAs). In order to examine differences in the presence of various health problems between multimorbid people and people with a single chronic disease, we performed a series of Chi-square tests and analyses of variance (ANOVAs) as well as a series of logistic regression analyses and analyses of covariance (ANCOVAs). The latter analyses were conducted to correct for possible differences between the two groups in the distribution of their age, gender, and illness duration. In order to investigate patterns of health problems among multimorbid people (research question 2), a hierarchical cluster analysis (complete linkage) was conducted [27]. This procedure, which is based on Euclidean distances, consists of dividing patients into clusters such that every patient belongs to only one cluster. This analysis was performed with the use of the six EQ-6D dimensions being the clustering variables and including the total group of multimorbid patients. In order to investigate the composition of the distinguished clusters of multimorbid patients according to their patient and illness characteristics, and to test for differences between the clusters in this respect (research question 3), we performed a series of Chi-square tests and analyses of variance (ANOVA's) with Bonferroni post hoc tests. Cluster membership was the independent variable.

\section{RESULTS}

\section{Characteristics and health problems of people with multiple versus one chronic disease}

The total sample consisted of 1092 people with one or more chronic diseases. Fiftyone per cent $(\mathrm{N}=561)$ had more than one chronic disease (Table 1). This sample of multimorbid people consisted of 297 (53\%) men and 264 (47\%) women aged between 20 and 91 years $(\mathrm{M}=65.58, \mathrm{SD}=13.33)$. Seven out of ten multimorbid people $(70 \%)$ were living with a partner. Cardiovascular diseases $(37 \%)$, diabetes $(29 \%)$, and arthritis $(28 \%)$ were most prevalent. The average post-diagnosis timespan of the first diagnosed chronic disease was 14.43 years $(\mathrm{SD}=9.61)$. As can be seen in Table 1, the 'one chronic disease' sample differs from the 'multimorbid' sample in almost every respect. For example, compared to people with one chronic disease, people with multiple chronic diseases were more often male; lower educated; a lower health literacy; a longer post-diagnosis time span; and a poorer medical health status on three out of four dimensions. The most prevalent diseases in the 'one chronic disease' group were diabetes $(16 \%)$, cardiovascular diseases (12\%), and asthma (11\%). Table 2 shows that compared to people with one chronic disease, multimorbid people experience more health problems within the domains of mobility, self-care, usual activities, pain/discomfort, and cognition. They also feel less happy and experience more loneliness. These differences partly relate 
Hopman, P., Schellevis, F.G., Rijken, M. Health-related needs of people with multiple chronic diseases: differences and underlying factors. Quality of Life Research: 2015

to differences between the two groups in demographic characteristics (age, gender) and illness duration: after correction for these characteristics, the differences between multimorbid people and people with one chronic disease regarding the presence of selfcare and cognitive problems no longer exist. This also holds for the initial differences in happiness and loneliness. What remains after correction is that a larger part of the people with multimorbidity experiences problems with mobility, usual activities, and pain/discomfort. Regardless of differences in age, gender, and illness duration, multimorbid people do not experience more problems within the domain anxiety/depression than people with one chronic disease, and they do not feel less satisfied with their current life

\section{Health problems among multimorbid people}

Full answers on the EQ-6D were missing for 24 participants therefore these people were excluded from further analyses. Cluster analysis revealed an eight-cluster solution as the optimal number of clusters that could explain the profile structure of the patients' self-reported problems (EQ-6D). Since four clusters contained six or less people, we decided to exclude these clusters and the 17 corresponding cases from further analyses, leaving four clusters (see Fig. 1; Table 3). Cluster 1 is the second largest cluster $(n=205)$, characterized by relatively many self-reported physical problems regarding mobility (77\%), performance of usual activities $(88 \%)$, and pain/discomfort (100\%), especially when compared to the third and fourth cluster (see Table 3 for Bonferroni post hoc results). Cluster $2(n=23)$ is characterized by multiple health problems. Not only are the proportions of selfreported problems regarding mobility $(87 \%)$, performance of usual activities (100 $\%)$, and pain discomfort (100\%) comparable to or even higher than in the first cluster, patients of this second cluster all experience anxiety and/or depression (100 $\%)$ and many of them also have problems with self-care (57\%). Cluster 3 is the largest cluster $(n=271)$, characterized by relatively few self-reported physical and mental health problems (B40\%), especially when compared to the first two clusters. Cluster $4(\mathrm{n}=21)$ is comparable to cluster 3 regarding favourable health outcomes (i.e. B43 \% reported problems). One major exception, however, is the proportion of self-reported cognitive problems in cluster $4(100 \%)$, which is higher than in any other cluster. Feelings of happiness, satisfaction, and loneliness differ across clusters as well. In line with the pattern of health problems, people in the first two clusters (reporting relatively many problems) are generally less happy, less satisfied, and lonelier than people in the third and fourth cluster (reporting relatively few problems; see Table 4 for Bonferroni post hoc results), especially people in the second cluster, who show negative outcomes on virtually all health dimensions, feel relatively unhappy, dissatisfied, and lonely.

[TABLE 1].

Characteristics associated with clusters of health problems among multimorbid patients

\section{Patient characteristics}

As shown in Table 5, the patient clusters associated with relatively many problems (i.e. clusters 1 and 2) contain more women than men, whereas the two other clusters 
Hopman, P., Schellevis, F.G., Rijken, M. Health-related needs of people with multiple chronic diseases: differences and underlying factors. Quality of Life Research: 2015

contain more men. People in cluster 2, experiencing the most problems, are younger than people in the other clusters. Living situation also varies between clusters, with more people living alone in cluster 2 than in cluster 3 . Health literacy is highest in cluster 3 , especially when compared to cluster 1 .

\section{Illness-related characteristics}

People in cluster 1 have more chronic diseases than people in cluster 3 (see Table 5). The prevalence of specific diseases was identical in all clusters, apart from arthritis: cluster 2 shows a relatively high prevalence of arthritis, especially when compared to cluster 3. No significant differences regarding illness duration were found between clusters. People in cluster 3 have a relatively favourable medical health status as assessed by their GP: in comparison with people in cluster 2 , their health status is less progressively deteriorating, and compared to people in cluster 1, their health status is considered more controllable by medical care. The degree to which patients' health statuses could be considered life threatening or episodic was identical in all clusters.

\section{[TABLE 2]. [FIGURE 1].}

\section{Discussion}

Considering the patient and illness-related characteristics people with multiple chronic diseases differ in almost every respect from people with a single chronic disease. Moreover, they also have more problems in almost all health domains, which partly relate to differences in age, gender, and illness duration. However, the amount to which multimorbid patients experience anxiety or depression seems to be comparable to that of people with one chronic disease. This raises the broader question whether psychological problems such as anxiety and depression mainly arise or worsen with the transition from not having a chronic disease to having one chronic disease, rather than the transition from having a single chronic disease to having multiple chronic diseases. The current data seem to support the former idea, which is also in line with research by Fortin and colleagues [28] who found that multimorbidity (as measured by the count of chronic diseases) was not related to psychological distress. When they accounted for disease severity, psychological distress did, however, increase with multimorbidity. Moreover, a study among almost 10,000 GP patients representative for the general Dutch population showed that $11.5 \%$ reported some or extreme anxiety or depression (this was measured with the EQ-6D as well; [19]). This proportion is only half as big as the proportion we found among people with one or more chronic diseases, which further supports the idea that psychological problems relate to (not) being chronically ill rather than to the number of chronic diseases people are diagnosed with. Almost half (44\%) of the multimorbid people have many health problems, in different health domains; especially within the physical functional domains (i.e. daily activities, mobility, and pain/discomfort), these people may have a strong need for care and support. Based on their self-reported health problems, the most vulnerable multimorbid people are more often female, have a smaller household size and are more often living alone, and have a lower health literacy. On the whole, they suffer from more chronic diseases and their health status is more progressively deteriorating and less controllable by medical care. A rather small subgroup (10\%) of the patients with 
Hopman, P., Schellevis, F.G., Rijken, M. Health-related needs of people with multiple chronic diseases: differences and underlying factors. Quality of Life Research: 2015

multimorbidity has not only many physical problems, but also many mental problems as well. Without exception, all people in this subgroup experience some or extreme feelings of anxiety and/or depression. These people are relatively young and often have problems with self-care as well.

About half (56\%) of the multimorbid people experience relatively few problems. Even compared to the health problems of people suffering from a single chronic condition (Table 1), their need for (more) support does not seem to be high. This is in line with GPs' assessments, i.e. that these patients' health statuses are not progressively deteriorating to a large extent and are fairly controllable by the medical care they receive. Besides their relatively favourable health condition, the fact that these people (compared to the other subgroups we distinguished) are more often living with a partner may also contribute to them experiencing fewer health problems. A partner may provide practical and emotional support [29], and he/she may also urge the patient to visit a doctor in case of (early) health problems. Remarkably, a small subgroup of the multimorbid patients with less health problems (i.e. $4 \%$ of the total number of multimorbid people) experiences cognitive problems and might thus have a need for (more) cognitive support. The vast majority $(71 \%)$ of these people is male, and they are relatively old.

Cardiovascular diseases seem to be somewhat more often present among these people, although not significantly (which may as well be a result of the small size of this group within the total sample). Givenn the relatively old age of these people, it may be possible that they suffer from common age-related symptoms of mild cognitive impairment (e.g. forgetfulness; [30]). A strength of this study is that it combines data retrieved from GP databases with self-reported data. More specifically, chronic diseases and the definition of multimorbidity are based on medical diagnoses by GPs, whereas health problems are based on patient health surveys. This is an elegant approach, since it thwarts contamination. Health-related needs of multimorbid people are hardly deducible from the type(s) of chronic diseases they suffer from. Only for one out of nine disease categories a difference in prevalence was found between the four clusters: arthritis is relatively more often present among multimorbid patients with more physical or multiple health problems (cluster 2). All in all, extensive needs for (more) care and support among people with multimorbidity seem to relate not only to the presence of more chronic diseases, but also to patient characteristics such as old age and not having a partner.

\section{[TABLE 3] [TABLE 4][TABLE 5].}

\section{Conclusions}

Based on the problems they experience, we conclude that patients with multimorbidity have relatively many and diverse health-related needs. Extensive health-related needs among people with multimorbidity may relate not only to the number of chronic diseases they suffer from, but also to their patient characteristics. This should be taken into account, when identifying target groups for comprehensive support programmes. 
Hopman, P., Schellevis, F.G., Rijken, M. Health-related needs of people with multiple chronic diseases: differences and underlying factors. Quality of Life Research: 2015

\section{Acknowledgments}

This research arises from the Joint Action on Chronic Diseases and Promoting Healthy Ageing Across the Life Cycle (JA-CHRODIS) which has received funding from the European Union, in the framework of the Health Programme (2008-2013). NIVEL has also received funding from the Netherlands Ministry of Health, Welfare and Sports to contribute to this joint action.

\section{Funding}

This study was funded by the Joint Action on Chronic

Diseases and Promoting Healthy Ageing Across the Life Cycle (JACHRODIS;

Grant Agreement No.: 20132201) and the Dutch Ministry

of Health, Welfare and Sport (Grant No.: 322095).

\section{Compliance with ethical standardsConflict of interest}

The authors have no competing interests to report.

\section{Ethical approval}

All procedures performed in studies involving human participants were in accordance with the ethical standards of the institutional and/or national research committee and with the 1964 Helsinki declaration and its later amendments or comparable ethical standards.

\section{Informed consent}

Informed consent was obtained from all individual participants included in the study.

\section{REFERENCES}

1. van Oostrom, S. H., Gijsen, R., Stirbu, I., Korevaar, J. C., Schellevis, F. G., H. S. J. Picavet, \& Hoeymans, N. (2014). Rise in the prevalence of chronic diseases and multimorbidity from 2001 to 2011 in the Dutch population, Manuscript submitted for publication.

2. Boyd, C., \& Fortin, M. (2010). Future of multimorbidity research: How should understanding of multimorbidity inform health system design? Public Health Reviews, 32, 451-474.

3. Uijen, A. A., \& van de Lisdonk, E. H. (2008). Multimorbidity in primary care: Prevalence and trend over the last 20 years. European Journal of General Practice, 14(1), 28-32. doi: 10 . 1080/13814780802436093.

4. Bower, P., Macdonald, W., Harkness, E., Gask, L., Kendrick, T., Valderas, J. M., et al. (2011). Multimorbidity, service organization and clinical decision making in primary care: A qualitative study. Family Practice, 28(5), 579-587. doi:10.1093/fampra/ cmr018.

5. Smith, S. M., Soubhi, H., Fortin, M., Hudon, C., \& O'Dowd, T. (2012). Managing patients with multimorbidity: Systematic review of interventions in primary care and community settings. Cochrane Database of Systematic Reviews, doi:10.1002/14651858.CD006560.pub2.

6. Marengoni, A., Angleman, S., Melis, R., Mangialasche, F., Karp, A., Garmen, A., et al. (2011). Aging with multimorbidity: A systematic review of the literature. Aging Research Reviews, 10, 430-439. doi:10.1016/j.arr2011.03.003.

7. Vogeli, C., Shields, A. E., Lee, T. A., Gibson, T. B., Marder, W. D., Weiss, K. B., et al. (2007). Multiple chronic conditions: Prevalence, health consequences, and implications for 
Hopman, P., Schellevis, F.G., Rijken, M. Health-related needs of people with multiple chronic diseases: differences and underlying factors. Quality of Life Research: 2015

quality, care management, and costs. Journal of General Internal Medicine, 22(Suppl. 3), 391-395. doi:10.1007/s11606-007-0322-1.

8. Fortin, M., Bravo, G., Hudon, C., Lapointe, L., Almirall, J., Dubois, M. F., et al. (2006). Relationship between multimorbidity and health-related quality of life of patients in primary care. Quality of Life Research, 15, 83-91.

9. Sprangers, M. A., de Regt, E. B., Andries, F., van Agt, H. M., Bijl, R. V., de Boer, J. B., et al. (2000). Which chronic conditions are associated with better or poorer quality of life? Journal of Clinical Epidemiology, 53(9), 895-907.

10. Rijken, M., van Kerkhof, M., Dekker, J., \& Schellevis, F. G. (2005). Comorbidity of chronic diseases: Effects of disease pairs on physical and mental functioning. Quality of Life Research, 14(1), 45-55. doi:10.1007/s11136-004-0616-2.

11. Rijken, M., Struckmann, V., Dyakova, M., Melchiorre, M. G., Rissanen, S., \& van Ginneken, E. (2013). ICARE4EU: Improving care for people with multiple chronic conditions in Europe. Eurohealth, 19(3), 29-31.

12. Ishikawa, H., \& Yano, E. (2008). Patient health literacy and participation in the healthcare process. Health Expectations, 11(2), 113-122. doi:10.1111/j.13697625.2008.00497.x.

13. de Bruin, S. R., Heijink, R., Lemmens, L., Struijs, J. N., \& Baan, C. A. (2011). Impact of disease management programs on healthcare expenditures for patients with diabetes, depression, heart failure or chronic obstructive pulmonary disease: A systematic review of the literature. Health Policy, 101, 105-121. doi:10.1016/j.healthpol.2011.03.006.

14. Boult, C., Green, A. F., Boult, L. B., Pacala, J. T., Snyder, C., \& Leff, B. (2009). Successful models of comprehensive care for older adults with chronic conditions: Evidence for the institute of medicine's "retooling for an Aging America" report. Journal of the American Geriatrics Society, 57, 2328-2337. doi:10.1111/j. 1532-5415.2009.02571.x.

15. Baanders, A. N., Rijken, P. M., \& Peters, L. (2002). Labour participation of the chronically ill: A profile sketch. European Journal of Public Health, 12(2), 124-130.

16. Hingstman, L., \& Kenens, R. J. (2009). Cijfers uit de registratie van huisartsen: Peiling 2009. Utrecht: NIVEL.

17. NIVEL. NIVEL Primary Care Database. http://www.nivel.nl/node/3418. Accessed on June 08, 2015.

18. Krabbe, P. F. M., Stouthard, M. E. A., Essink-Bot, M. L., \& Bonsel, G. J. (1999). The effect of adding a cognitive dimension to the EuroQol multiattribute health-status classification system. Journal of Clinical Epidemiology, 52, 293-301. doi:10.1016/S08954356(98)00163-2.

19. Hoeymans, N., van Lindert, H., \& Westert, G. P. (2005). The health status of the Dutch population as assessed by the EQ-6D. Quality of Life Research, 14(3), 655-663. doi:10.1007/s11136-004-1214-z.

20. Brooks, R. (1996). EuroQol: The current state of play. Health Policy, 37, 53-72.

21. de Jong-Gierveld, J., \& Kamphuis, F. H. (1985). The development of a Rasch-type loneliness-scale. Applied Psychological Measurement, 9, 289-299. doi:10.1177/014662168500900307.

22. van Tilburg, T. G., \& de Leeuw, E. D. (1991). Stability of scale quality under various data collection procedures: A mode comparison of the "De Jong-Gierveld Loneliness Scale.". International Journal of Public Opinion Research, 3, 69-85. doi:10.1093/ijpor/3.1.69.

23. van Knippenberg, F. C., \& de Haes, J. C. (1988). Measuring the quality of life of cancer patients: Psychometric properties of instruments. Journal of Clinical Epidemiology, 41(11), 1043-1053.

24. Ishikawa, H., Takeuchi, T., \& Yano, E. (2008). Measuring functional, communicative and critical health literacy among diabetic patients. Diabetes Care, 31, 874-879. doi:10.2337/dc07-1932.

25. Lamberts, H., \& Wood, M. (1987). International classification of primary care. Oxford: Oxford University Press.

26. Nationale Raad voor de Volksgezondheid. Standaardisatie van chroniciteitsbegrippen. Vooronderzoek naar het definie"ren en specificeren van chroniciteit van gezondheidsproblemen ten behoeve van classificaties. Zoetermeer, The Netherlands: Nationale Raad voor de Volksgezondheid, 1995. 
Hopman, P., Schellevis, F.G., Rijken, M. Health-related needs of people with multiple chronic diseases: differences and underlying factors. Quality of Life Research: 2015

27. Stata.com (2014). Cluster analysis. Retrieved from http://www.stata.com/features/clusteranalysis/ on December 12, 2014.

28. Fortin, M., Bravo, G., Hudon, C., Lapointe, L., Dubois, M. F., \& Almirall, J. (2006).

Psychological distress and multimorbidity in primary care. Annals of Family Medicine, 4, 417-422.

29. Thoits, P. A. (1986). Social support as coping assistance. Journal of Consulting and Clinical Psychology, 54(4), 416-423.

30. Gauthier, S., Reisberg, B., Zaudig, M., et al. (2006). Mild cognitive impairment. Lancet, 367, 1262-1270. doi:10.1016/S0140-6736(06)68542-5. 
Hopman, P., Schellevis, F.G., Rijken, M. Health-related needs of people with multiple chronic diseases: differences and underlying factors. Quality of Life Research: 2015

\section{TABLES AND FIGURES}

Table 1 Patient and illness-related characteristics of people with multimorbidity and people with one chronic disease $(N=1.092)$

\begin{tabular}{|c|c|c|c|c|c|c|c|}
\hline & \multicolumn{2}{|c|}{ Multimorbid $(n=561)$} & \multicolumn{4}{|c|}{ One chronic disease $(n=531)$} & \multirow[t]{2}{*}{$F / x^{2}(\mathrm{df}), p$} \\
\hline & $n$ & $\%$ & $n$ & & $\%$ & & \\
\hline \multicolumn{8}{|l|}{ Patient characteristics } \\
\hline \multicolumn{8}{|l|}{ Gender } \\
\hline Male & 297 & 53 & \multicolumn{2}{|l|}{229} & \multicolumn{2}{|l|}{43} & \multirow[t]{2}{*}{$\chi^{2}(1)=10.53, p<.001$} \\
\hline Female & 264 & 47 & 302 & & 57 & & \\
\hline Age $(M, \mathrm{SD})$ & \multicolumn{2}{|l|}{$65.58(13.33)$} & \multicolumn{4}{|c|}{$56.65(15.14)$} & $F(1,1090)=107.18, p<.001$ \\
\hline \multicolumn{8}{|l|}{ Education level } \\
\hline Low & 205 & 37 & 115 & & 22 & & \multirow[t]{3}{*}{$\chi^{2}(2)=30.55, p<.001$} \\
\hline Moderate & 211 & 39 & 263 & & 51 & & \\
\hline High & 131 & 24 & 140 & & 27 & & \\
\hline \multicolumn{8}{|l|}{ Ethnicity } \\
\hline Native Dutch & 504 & 90 & 498 & & 94 & & \multirow[t]{3}{*}{$\chi^{2}(2)=6.04, p<.05$} \\
\hline Non-native Dutch (Westem) & 47 & 8 & 25 & & 5 & & \\
\hline Non-native Dutch (non-Western) & 8 & 1 & 8 & & 2 & & \\
\hline \multicolumn{8}{|l|}{ Living situation } \\
\hline Without a partner & 167 & 30 & 142 & & 27 & & \multirow[t]{2}{*}{$\chi^{2}(1)=1.23$, n.s. } \\
\hline With a partner & 391 & 70 & 386 & & 73 & & \\
\hline Health Literacy $(1-4 ; M, \mathrm{SD})$ & \multicolumn{2}{|l|}{$3.3(.59)$} & \multicolumn{4}{|c|}{$3.5(.58)$} & $F(1,773)=14.31, p<.001$ \\
\hline \multicolumn{8}{|l|}{ Illness-related characteristics } \\
\hline \multicolumn{8}{|l|}{ Chronic disease(s) } \\
\hline Cardiovascular & 207 & 37 & \multicolumn{2}{|l|}{65} & \multicolumn{2}{|l|}{12} & $\chi^{2}(1)=88.67, p<.001$ \\
\hline Diabetes & 164 & 29 & \multicolumn{2}{|l|}{87} & \multicolumn{2}{|l|}{16} & $\chi^{2}(1)=25.44, p<.001$ \\
\hline Arthritis & 157 & 28 & \multicolumn{2}{|l|}{44} & \multicolumn{2}{|l|}{8} & $\chi^{2}(1)=70.49, p<.001$ \\
\hline Asthma & 74 & 13 & \multicolumn{2}{|l|}{59} & 11 & & $\chi^{2}(1)=1.10$, n.s. \\
\hline Cancer & 82 & 15 & 33 & & 6 & & $\chi^{2}(1)=20.44, p<.001$ \\
\hline Neurological & 68 & 12 & 45 & & 8 & & $\chi^{2}(1)=3.91, p<.05$ \\
\hline COPD & 65 & 12 & 32 & & 6 & & $\chi^{2}(1)=10.42, p<.001$ \\
\hline Digestive & 66 & 12 & 28 & & 5 & & $\chi^{2}(1)=14.62, p<.001$ \\
\hline Other(s) & 357 & 64 & 138 & & 26 & & $\chi^{2}(1)=156.02, p<.001$ \\
\hline & & & $M$ & SD & $M$ & SD & \\
\hline Illness duration (based on first diag & ed chronic dise & years) & 14.43 & 9.61 & 9.17 & 7.49 & $F(1,1077)=99.70, p<.001$ \\
\hline Health status: life threateningness & & & 1.37 & .58 & 1.22 & .47 & $F(1,1045)=19.97, p<.001$ \\
\hline Health status: progressive deteriora & $(1-3)$ & & 1.70 & .76 & 1.48 & .68 & $F(1,1046)=26.56, p<.001$ \\
\hline Health status: episodic course (1-3 & & & 1.98 & .81 & 1.84 & .83 & $F(1,1077)=7.46, p<.01$ \\
\hline Health status: medical controllabili & (1-3) & & 2.29 & 65 & 2.35 & .71 & $F(1,1077)=2.37$, n.s. \\
\hline
\end{tabular}

n.s. not significant 
Hopman, P., Schellevis, F.G., Rijken, M. Health-related needs of people with multiple chronic diseases: differences and underlying factors. Quality of Life Research: 2015

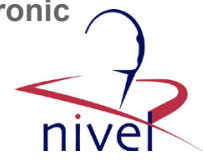

Table 2 Self-reported problems, happiness, satisfaction, and loneliness of people with multimorbidity versus one chronic disease $(N=1.092)$

\begin{tabular}{|c|c|c|c|c|c|c|c|c|}
\hline & & \multicolumn{2}{|c|}{$\begin{array}{l}\text { Multimorbid } \\
(n=561)^{*}\end{array}$} & \multicolumn{3}{|c|}{$\begin{array}{l}\text { One chronic disease } \\
(n=531)^{*}\end{array}$} & \multirow[t]{2}{*}{$p$ uncorrected } & \multirow[t]{2}{*}{$p$ corrected $* *$} \\
\hline & & $n$ & $\%$ & $n$ & & $\%$ & & \\
\hline \multicolumn{2}{|c|}{ EQ-6D Mobility: some/extreme problems } & 258 & 46.7 & 158 & & 30.0 & $p<.001$ & $p<.005$ \\
\hline \multicolumn{2}{|c|}{ EQ-6D Self-care: some/extreme problems } & 66 & 12.0 & 36 & & 6.8 & $p<.005$ & n.s. \\
\hline \multicolumn{2}{|c|}{ EQ-6D Usual activities: some/extreme problems } & 249 & 44.9 & 183 & & 34.6 & $p<.001$ & $p<.05$ \\
\hline \multicolumn{2}{|c|}{ EQ-6D Pain/discomfort: some/extreme problems } & 373 & 67.5 & 290 & & 55.1 & $p<.001$ & $p<.001$ \\
\hline \multicolumn{2}{|c|}{ EQ-6D Anxiety/depression: some/extreme problems } & 121 & 21.9 & 105 & & 20.0 & n.s. & n.s. \\
\hline \multicolumn{2}{|c|}{ EQ-6D cognition: some/extreme problems } & 136 & 24.9 & 102 & & 19.3 & $p<.05$ & n.s. \\
\hline & $M$ & SD & $M$ & & SD & & & \\
\hline Happiness (1-5) & 3.78 & .79 & 3.87 & & .74 & & $p<.05$ & n.s. \\
\hline Satisfaction (1-5) & 3.15 & 1.01 & 3.23 & & .96 & & n.s. & n.s. \\
\hline Loneliness (0-11) & 3.39 & 3.33 & 2.79 & & 3.20 & & $p<.005$ & n.s. \\
\hline
\end{tabular}

n.s. not significant

* Uncorrected values

** Corrected for age, gender, and illness duration (based on first diagnosed chronic disease, in years)

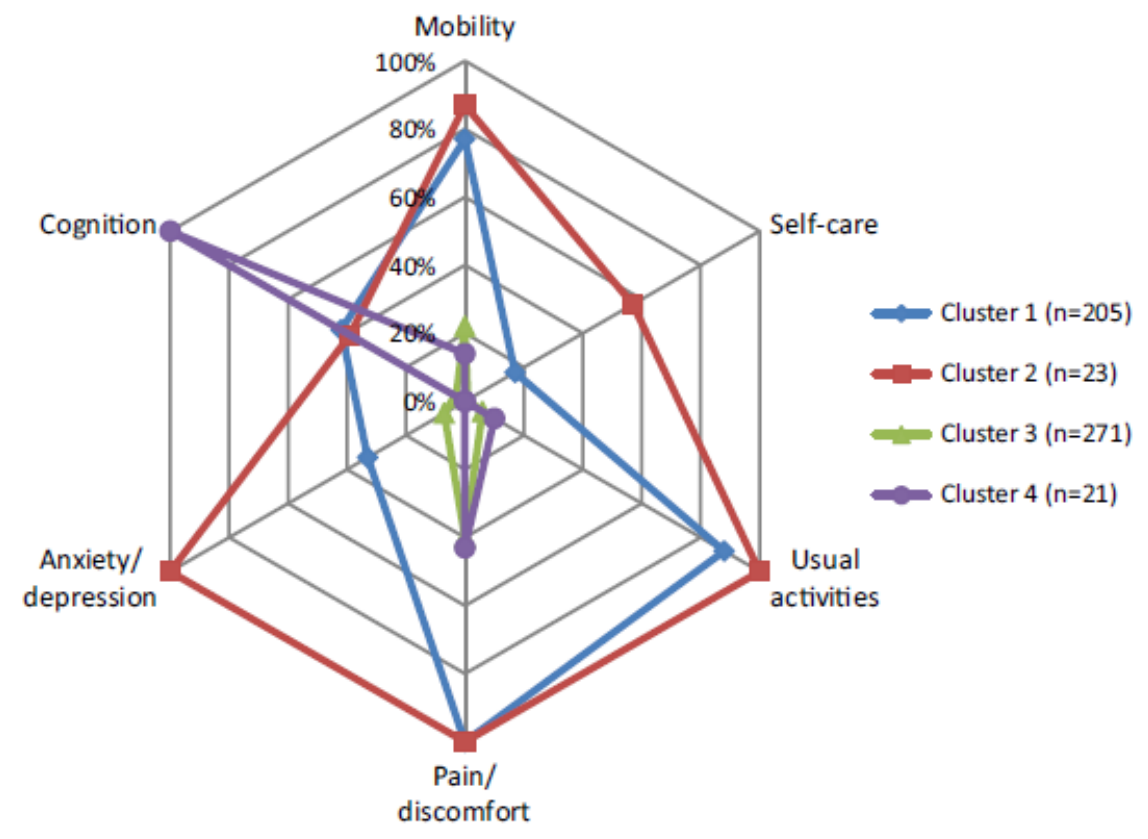

Fig. 1 Description of multimorbidity clusters according to percentage of people reporting a problem ('some' or 'extreme') in each of the EQ-6D dimensions $(N=520)$ 
Hopman, P., Schellevis, F.G., Rijken, M. Health-related needs of people with multiple chronic diseases: differences and underlying factors. Quality of Life Research: 2015

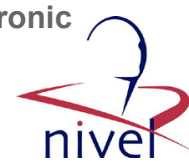

Table 3 Description of multimorbidity clusters according to percentage of people reporting a problem ('some' or 'extreme') in each of the EQ$6 \mathrm{D}$ dimensions $(N=520)$

\begin{tabular}{lccccc}
\hline & $\begin{array}{l}\text { Cluster 1 }(n=205) \\
\%\end{array}$ & $\begin{array}{l}\text { Cluster 2 }(n=23) \\
\%\end{array}$ & $\begin{array}{l}\text { Cluster 3 } \\
\%\end{array}$ & \multicolumn{2}{l}{$\begin{array}{l}\text { Cluster 4 }(n=21) \\
\chi^{2}(\mathrm{df}), p\end{array}$} \\
\hline Mobility & $77.1^{\mathrm{a}}$ & $87.0^{\mathrm{a}}$ & $21.8^{\mathrm{b}}$ & $14.3^{\mathrm{b}}$ & $\chi^{2}(3)=167.68, p<.001$ \\
Self-care & $17.1^{\mathrm{a}}$ & $56.5^{\mathrm{b}}$ & $1.1^{\mathrm{a}}$ & $0.0^{\mathrm{a}}$ & $\chi^{2}(3)=94.45, p<.001$ \\
Usual activities & $87.8^{\mathrm{a}}$ & $100.0^{\mathrm{a}}$ & $6.3^{\mathrm{b}}$ & $9.5^{\mathrm{b}}$ & $\chi^{2}(3)=357.76, p<.001$ \\
Pain/discomfort & $100.0^{\mathrm{a}}$ & $100.0^{\mathrm{a}}$ & $40.0^{\mathrm{b}}$ & $42.9^{\mathrm{b}}$ & $\chi^{2}(3)=206.03, p<.001$ \\
Anxiety/depression & $33.2^{\mathrm{a}}$ & $100.0^{\mathrm{b}}$ & $6.6^{\mathrm{c}}$ & $0.0^{\mathrm{ac}}$ & $\chi^{2}(3)=144.28, p<.001$ \\
Cognition & $42.4^{\mathrm{a}}$ & $39.1^{\mathrm{a}}$ & $2.6^{\mathrm{b}}$ & $100.0^{\mathrm{c}}$ & $\chi^{2}(3)=176.52, p<.001$ \\
\hline
\end{tabular}

a,b Bonferroni post hoc tests showed that values with different subscripts differ significantly at the level of at least $<.05$ (where, for example, 'a' differs from ' $b$ ' but not from ' $a b$ ')

Table 4 Happiness, satisfaction with life, and loneliness of people within the multimorbidity clusters $(N=520 ; M$, SD)

\begin{tabular}{llllll}
\hline & Cluster 1 $(n=205)$ & Cluster 2 $(n=23)$ & Cluster 3 $(n=271)$ & Cluster 4 $(n=21)$ & $F(\mathrm{df}), p$ \\
\hline Happiness (1-5) & $3.54(.72)^{\mathrm{a}}$ & $2.43(1.08)^{\mathrm{b}}$ & $4.10(.58)^{\mathrm{c}}$ & $4.05(.60)^{\mathrm{a}, \mathrm{c}}$ & $F(3,514)=61.22, p<.001$ \\
Life satisfaction (1-5) & $2.71(.91)^{\mathrm{a}}$ & $1.74(.92)^{\mathrm{b}}$ & $3.64(.78)^{\mathrm{c}}$ & $3.48(.60)^{\mathrm{c}}$ & $F(3,515)=73.08, p<.001$ \\
Loneliness (0-11) & $4.37(3.68)^{\mathrm{a}}$ & $7.04(3.90)^{\mathrm{b}}$ & $2.34(2.53)^{\mathrm{c}}$ & $2.79(2.10)^{\mathrm{a}, \mathrm{c}}$ & $F(3,476)=26.91, p<.001$
\end{tabular}

a,b Bonferroni post hoc tests showed that values with different subscripts differ significantly at the level of at least $<.05$ (where, for example, ' $a$ ' differs from ' $b$ ' but not from ' $a b$ ') 
Hopman, P., Schellevis, F.G., Rijken, M. Health-related needs of people with multiple chronic diseases: differences and underlying factors. Quality of Life Research: 2015

Table 5 Patient and illness-related characteristics of people within the multimorbidity clusters $(N=520)$

\begin{tabular}{|c|c|c|c|c|c|}
\hline & $\begin{array}{l}\text { Cluster } 1 \\
(n=205)\end{array}$ & $\begin{array}{l}\text { Cluster } 2 \\
(n=23)\end{array}$ & Cluster $3(n=271)$ & $\begin{array}{l}\text { Cluster } 4 \\
(n=21)\end{array}$ & $\chi^{2} / F(\mathrm{df}), p$ \\
\hline \multicolumn{6}{|l|}{ Patient characteristics } \\
\hline \multicolumn{6}{|l|}{ Gender } \\
\hline Male & $46 \%$ & $43 \%$ & $59 \%$ & $71 \%$ & \multirow[t]{2}{*}{$\chi^{2}(3)=10.78, p=.013$} \\
\hline Female & $54 \%$ & $57 \%$ & $41 \%$ & $29 \%$ & \\
\hline Age (in years; $M, \mathrm{SD}$ ) & $66.30(12.62)^{\mathrm{a}}$ & $56.65(14.73)^{\mathrm{b}}$ & $64.77(13.87)^{\mathrm{a}}$ & $70.10(12.84)^{\mathrm{a}}$ & $F(3,516)=4.62, p<.005$ \\
\hline \multicolumn{6}{|l|}{ Education level $(N=506)$} \\
\hline Low & $39 \%$ & $39 \%$ & $33 \%$ & $38 \%$ & \multirow[t]{3}{*}{$\chi^{2}(6)=6.86$, n.s. } \\
\hline Moderate & $41 \%$ & $35 \%$ & $38 \%$ & $29 \%$ & \\
\hline Higher & $20 \%$ & $26 \%$ & $29 \%$ & $33 \%$ & \\
\hline \multicolumn{6}{|l|}{ Ethnicity $(N=518)$} \\
\hline Native Dutch & $89 \%$ & $83 \%$ & $92 \%$ & $95 \%$ & \multirow[t]{3}{*}{$\chi^{2}(6)=10.24$, n.s. } \\
\hline Non-native Dutch (Westem) & $9 \%$ & $9 \%$ & $7 \%$ & $5 \%$ & \\
\hline Non-native Dutch (non-Western) & $2 \%$ & $9 \%$ & $1 \%$ & $0 \%$ & \\
\hline \multicolumn{6}{|l|}{ Living situation $(N=518)$} \\
\hline Without a partner & $36 \%$ & $43 \%$ & $24 \%$ & $33 \%$ & \multirow[t]{2}{*}{$\chi^{2}(3)=9.88, p<.05$} \\
\hline With a partner & $64 \%$ & $57 \%$ & $76 \%$ & $67 \%$ & \\
\hline Health literacy $(N=380)(1-4 ; M, \mathrm{SD})$ & $3.23(.58)^{\mathrm{a}}$ & $3.17(.59)^{\mathrm{a}, \mathrm{b}}$ & $3.46(.57)^{\mathrm{b}}$ & $3.13(.59)^{\mathrm{a}, \mathrm{b}}$ & $F(3,376)=6.06, p<.001$ \\
\hline \multicolumn{6}{|l|}{ Illness-related characteristics } \\
\hline \multicolumn{6}{|l|}{ Chronic disease(s) } \\
\hline Cardiovascular & $34 \%$ & $26 \%$ & $39 \%$ & $43 \%$ & $\chi^{2}(3)=2.52$, n.s. \\
\hline Diabetes & $29 \%$ & $30 \%$ & $29 \%$ & $14 \%$ & $\chi^{2}(3)=2.23$, n.s. \\
\hline Arthritis & $33 \%$ & $52 \%$ & $22 \%$ & $19 \%$ & $\chi^{2}(3)=14.44, p<.005$ \\
\hline Asthma & $14 \%$ & $13 \%$ & $14 \%$ & $10 \%$ & $\chi^{2}(3)=30$, n.s. \\
\hline Cancer & $13 \%$ & $4 \%$ & $17 \%$ & $0 \%$ & $\chi^{2}(3)=7.47, p=.058$ \\
\hline Neurological & $13 \%$ & $26 \%$ & $10 \%$ & $14 \%$ & $\chi^{2}(3)=5.70$, n.s. \\
\hline COPD & $11 \%$ & $9 \%$ & $11 \%$ & $14 \%$ & $\chi^{2}(3)=.35$, n.s. \\
\hline Digestive & $12 \%$ & $17 \%$ & $10 \%$ & $29 \%$ & $\chi^{2}(3)=6.86, p=.077$ \\
\hline Other(s) & $67 \%$ & $43 \%$ & $63 \%$ & $67 \%$ & $\chi^{2}(3)=5.02$, n.s. \\
\hline$N$ of chronic diseases $(M, \mathrm{SD})$ & $2.68(.77)^{\mathrm{a}}$ & $2.48(.79)^{\mathrm{a}, \mathrm{b}}$ & $2.42(.69)^{\mathrm{b}}$ & $2.52(.75)^{\mathrm{a}, \mathrm{b}}$ & $F(3,516)=4.88, p<.005$ \\
\hline Illness duration & $15.16(10.40)$ & $12.71(8.14)$ & $13.70(9.13)$ & $13.29(4.65)$ & $F(3,516)=1.20$, n.s. \\
\hline $\begin{array}{l}\text { Health status: life threateningness } \\
\qquad(1-3 ; M, \mathrm{SD})\end{array}$ & $1.36(.56)$ & $1.52(.73)$ & $1.32(.55)$ & $1.22(.43)$ & $F(3,485)=1.25$, n.s. \\
\hline $\begin{array}{l}\text { Health status: progressive deterioration } \\
(1-3 ; M, \mathrm{SD})\end{array}$ & $1.74(.75)^{\mathrm{a}, \mathrm{b}}$ & $2.13(.81)^{\mathrm{a}}$ & $1.58(.73)^{\mathrm{b}}$ & $1.61(.78)^{\mathrm{a}, \mathrm{b}}$ & $F(3,486)=4.75, p<.005$ \\
\hline $\begin{array}{l}\text { Health status: episodic course } \\
(1-3 ; M, \mathrm{SD})\end{array}$ & $1.95(.77)$ & $1.83(.72)$ & $1.99(.83)$ & $2.20(.89)$ & $F(3,510)=.91$, n.s. \\
\hline $\begin{array}{l}\text { Health status: medical controllability } \\
(1-3 ; M, \mathrm{SD})\end{array}$ & $2.16(.64)^{\mathrm{a}}$ & $2.09(.67)^{\mathrm{a}, \mathrm{b}}$ & $2.42(.62)^{\mathrm{b}}$ & $2.50(.69)^{\mathrm{a}, \mathrm{b}}$ & $F(3,506)=7.84, p<.001$ \\
\hline
\end{tabular}

n.s. not significant

a,b Bonferroni post hoc tests showed that values with different subscripts differ significantly at the level of at least $<05$ (where, for example, ' $a$ ' differs from ' $b$ ' but not from ' $a b$ ') 